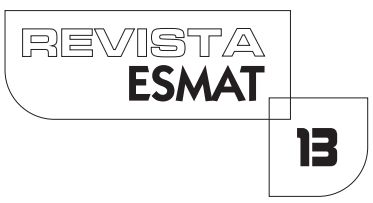

\title{
O PRINCÍPIO DA GESTÃO RACIONAL DOS RECURSOS HÍDRICOS COMO PRINCÍPIO DE DIREITO INTERNACIONAL E AMBIENTAL ${ }^{1}$
}

THE PRINCIPLE OF RATIONAL MANAGEMENT OF HYDRIC RESOURCES AS A PRINCIPLE OF INTERNATIONAL AND ENVIRONMENTAL LAW

Carla Amado Gomes

Professora da Faculdade de Direito da Universidade de Lisboa. Professora Convidada da Faculdade de Direito da Universidade Católica Portuguesa (Porto)

\section{RESUMO}

Aágua, enquanto recurso tridimensional - de carácter económico, social e ambiental -é um bem que requer especiais medidas de gestão, dadas a sua escassez e a essencialidade à vida. O princípio da gestão racional da água, tendo começado por se manifestar sob a veste de metodologia de gestão de recursos hídricos partilhados, é hoje um princípio de aplicação genérica a todo o tipo de recursos hídricos, embora a sua consagração seja fundamentalmente sediada em documentos de soft law.

PALAVRAS-CHAVE: Água; Direito à água; Princípio da gestão racional

\section{ABSTRACT}

Water, as a trimensional resource - economic, social and environmental - is a common good which involves specific management measures due to its scarcity and essenciality for life. The principle of rational management, although in the beginning linked to the management of shared hidric resources, is today a principle which applies to all hidric resources, shared or not - even if, for now, it is still based in soft law documents.

KEYWORDS: Water; Right to water; Principle of rational management

\footnotetext{
'Uma versão mais extensa deste texto contou com a colaboração do doutor Rodrigo Rondon, a quem agradeço os preciosos contributos. Foi preservada a oralidade, por isso se encontrando o texto limpo de referências bibliográficas, que vão indicadas a final.
} 


\section{I ÁGUA: UM RECURSO SOCIAL, ECONÓMICO EAMBIENTAL}

Quando vemos imagens da Terra a partir do espaço extra-atmosférico, ficamos iluminados por uma sensação de azul e de que a água abunda, e, na verdade, 70\% do Planeta é coberto por água. Porém, apenas $3 \%$ da água existente no mundo é água potável, e 2/3 da água existente está enclausurada em glaciares e noutros locais inacessíveis, ou é imprópria para consumo. A pressão demográfica, bem como as guerras, a falta de infraestruturas, a agricultura (e a pecuária), e as alterações climáticas agravam essa escassez. Mais de metade das zonas húmidas da Terra desapareceram, e os casos de poluição do meio hídrico aumentam a indisponibilidade do recurso.

Cerca de um bilhão de pessoas não tem acesso à água e mais de dois bilhões e meio enfrentam dificuldades de abastecimento pelo menos uma vez por ano. Esses problemas se reflectem não só no plano do consumo, como também no âmbito das falhas de saneamento, que afectam quase um bilhão e meio de pessoas expostas a doenças várias relacionadas com a escassez de água. Estima-se que, por este andar, em 2050, mais de dois terços da população mundial enfrentem escassez de água.

O Sul da Europa é frequentemente apontado como uma das regiões potencialmente mais afectadas pelo aquecimento global. Várias previsões apontam para uma redução progressiva da disponibilidade de água, com alterações significativas dos níveis médios de escoamento e de intensificação da sazonalidade, bem como para um aumento de problemas relacionados com a qualidade da água devido à subida das temperaturas e à ocorrência de fenómenos climáticos extremos, tocando sectoreschave da economia e também os equilíbrios dos ecossistemas. Em Portugal, viveu-se a última situação de seca extrema severa, em 20।5, com 80\% do território continental afectado. A seca tem consequências nocivas em vários planos, desde o agravamento do risco de incêndio, passando pelas perdas de rendimento agrícola e alta de preços dos produtos, até à conservação das espécies.

No Direito português, a tridimensionalidade do recurso natural "água" fica desde logo bem vincada no artigo 10 da Lei de Bases do Ambiente (Lei n 19, de 2014, de 14 de abril), em que se enunciam os componentes ambientais naturais. Sinais idênticos detectam-se na Lei da Água (Lei n 58, de 2005, de 29 de dezembro, com última alteração pela Lei n 130, de 20 I2, de 22 de junho, da Lei da Água, que enuncia estas três dimensões nas alíneas a), b) e c) do $n^{\circ}$ I do artigo $3^{\circ}$ :

a) Princípio do valor social da água, que consagra o acesso universal à água para as necessidades humanas básicas, a custo socialmente aceitável, e sem constituir fator de discriminação ou exclusão;

b) Princípio da dimensão ambiental da água, nos termos do qual se reconhece a necessidade de um elevado nível de proteção da água, de modo a garantir a sua utilização sustentável;

c) Princípio do valor económico da água, por força do qual se 
consagra o reconhecimento da escassez atual ou potencial deste recurso e a necessidade de garantir a sua utilização economicamente eficiente, com a recuperação dos custos dos serviços de águas, mesmo em termos ambientais e de recursos, e tendo por base os princípios do poluidor-pagador e do utilizador-pagador (...).

Este diploma acompanha as mais recentes tendências em sede de valorização do recurso e de consciencialização para o seu uso racional, de resto um dos 17 Objectivos da Agenda 2030 da Organização das Nações Unidas (Objetivo 6: Água potável e saneamento). Com efeito, como recurso econômico, a água é reconhecidamente um recurso escasso e de grande utilidade. A categoria de usos compreendidos na dimensão económica da água abrange usos industriais; o tratamento, transporte e distribuição de água urbana; a coleta e o tratamento de seus efluentes; o transporte; e a geração de energia. Assim, as políticas públicas e instituições relacionadas com tais usos compreendem a definição de direitos de propriedade, alocação de recursos, regulação de infraestrutura e organização industrial.

Já enquanto recurso de dimensão social, os recursos hídricos estão associados à satisfação de necessidades humanas básicas - nomeadamente, o acesso à água para consumo, para confecção de alimentos, para higiene. Nessa perspectiva, trata-se de garantir um nível de atendimento mínimo a toda a sociedade ("minimum standards" e "universal service") e de implementar políticas públicas de erradicação da pobreza e da desigualdade social, as quais, na maior parte das vezes, se traduzem na atribuição de subsídios diretos e indiretos.

Finalmente, do ponto de vista ambiental/ecológico, a água é essencial ao equilíbrio do ecossistema, tanto aquífero como terrestre. Estão aqui em causa, por um lado, as medidas de aproveitamento racional que assegurem a manutenção do ciclo hidrológico e evitem o esgotamento do recurso na sua qualidade de fonte de vida e de habitat (tanto em situações de normalidade como de stress hídrico) e, por outro lado, a prevenção da poluição, que degrada a qualidade do meio hídrico e põe em risco as espécies que nela habitam e que dele se alimentam.

É importante destacar que tais "categorias de usos" não são excludentes, antes se complementam. É esta a lógica da fórmula da gestão integrada de recursos hídricos Integrated Water Resources Management (IWRM). Esse conceito tem sido amplamente adotado desde os anos 1990, tanto para efeito de análise acadêmica como para a formulação de políticas públicas². Segundo a Global Water Partnership - organização

${ }^{2} \mathrm{Cfr}$. The Dublin Statement on Water and Sustainable Development, adoptado em 3 I de Janeiro de 1992 na sequência da Conferência Internacional sobre Água e Ambiente, que teve lugar em Dublin. Um exemplo da repercussão do conceito de IWRM pode constatar-se na sua inscrição, logo em 1993, nas Diretivas Operacionais do Banco Mundial —The World Bank, OP 4.07 Water Resources Management: A World Bank Policy Paper, 8(1993). 
criada em 1996 como veículo para o desenvolvimento do IWRM -, a gestão integrada de recursos hídricos consiste em "um processo para promoção do desenvolvimento e da gestão coordenada de recursos hídricos, solo e recursos relacionados, a fim de maximizar o bem-estar econômico e social resultante, de forma equitativa, sem comprometer a sustentabilidade dos ecossistemas vitais" ${ }^{3}$.

No plano constitucional português, a protecção dos recursos hídricos passa normalmente pela consagração da sua natureza pública, sempre que susceptíveis de aproveitamento de utilidade pública (vide, no caso português, o artigo 84\%/l/a) e c) da Constituição da República Portuguesa (CRP); bem assim como o regime descrito na Lei $n^{\circ}$ 54, de 2005, de 15 de novembro, que estabelece a titularidade dos recursos hídricos), mas algumas Constituições têm mesmo avançado, nos últimos anos, para a consagração de um "direito à água" (casos como o Equador (2008), a Bolívia (2009), a Tunísia (20|4)), ou para a explicitação de um "direito de acesso à água" (Honduras ( 1 982, revista em 20 I3); Quénia (20 I 9); Marrocos (20 I 2)). Certo é que se trata de um recurso natural multifuncional, cuja existência é vital ao ser humano quer directa, quer indirectamente.

\section{O APROVEITAMENTO RACIONAL DOS RECURSOS HÍDRICOS NA PERSPECTIVA DE DIREITO INTERNACIONAL}

\section{I Direito Internacional e recursos hídricos: as origens.}

tratamento jurídico do tema do aproveitamento dos recursos hídricos na perspectiva do Direito Internacional moderno não é recente. A partir da consagração do princípio da liberdade de navegação no Tratado de Vestfália (1648), alguns tratados internacionais que o sucederam já continham provisões acerca de apropriações e obras hidráulicas. A partir de então, na Europa do século XVIII, começam a surgir as primeiras iniciativas de enquadramento jurídico do aproveitamento de recursos hídricos compartilhados, inscritos em tratados bilaterais celebrados entre os Estados em cujos territórios se situam tais recursos, até mesmo com a criação de organizações para a sua gestão (ressalte-se a criação da Comissão Central para a navegação do Reno, em I 868, a mais antiga organização internacional do mundo). No entanto, não há registro de tentativas de elaboração de normas gerais de Direito Internacional sobre o aproveitamento de recursos hídricos antes do século $X X^{4}$.

${ }^{3} \mathrm{O}$ conceito de IWRM está alicerçado nos Princípios de Dublin - ver infra.

${ }^{4} U \mathrm{~m}$ das exceções é a Convention and Statute on the Regime of Navigable Waterways of International Concern, datada de 20 de Abril de 1921, in League of Nations, Treaty Series, Vol. VII, p. 37. Veja-se também a Primeira Resolução do Institut de Droit International sobre rios internacionais de 191 I, intitulada International Regulations Regarding the Use of International 
Somente a partir da década de 1970 se inicia o processo de codificação e progressivo desenvolvimento do Direito Internacional no tocante aos recursos hídricos compartilhados para usos não navegáveis, e também por essa altura despontam os primeiros debates sobre o problema das crises hídricas e da sua relação com os direitos humanos, com o desenvolvimento económico e com a protecção do ambiente. Em 1970, a Assembleia Geral das Nações Unidas (ONU) solicitou à Comissão de Direito Internacional $(\mathrm{CDI})$ a preparação de estudos sobre o tópico dos cursos de água internacionais. Paralelamente, em 1972, a Organização das Nações Unidas organizou a Primeira Conferência Mundial em tema de Protecção do Ambiente, da qual resultou a Declaração de Estocolmo, na qual se inscreveu o princípio de que os recursos hídricos, assim como outros recursos naturais, devem ser salvaguardados em benefício da presente e das futuras gerações, por meio de prudente planejamento e gestão (princípio 2).

Na sequência do despertar das preocupações de preservação dos recursos naturais do Planeta, teve lugar, em 1977, a Primeira Conferência da Organização das Nações Unidas sobre a água, em Mar del Plata (Argentina). Essa conferência é considerada um marco na história da gestão de recursos hídricos e na discussão sobre o direito (humano) à água. No âmbito dessa conferência, foi adoptado o chamado Plano de Ação de Mar del Plata, o primeiro instrumento abrangente e detalhado com recomendações sobre a gestão de recursos hídricos, que foi posteriormente aprovado pela Assembleia Geral da Organização das Nações Unidas e incluído nos documentos de trabalho da CDI.

A partir da década de 1990, fica amplamente reconhecido pela comunidade internacional que o agravamento dos problemas de escassez hídrica tem relevante impacto no desenvolvimento socioeconómico, reconhecimento que justificará a inserção do tema da "crise hídrica global" nas agendas governamentais supranacionais de forma mais profunda e abrangente, ou seja, não apenas restrita aos aspectos transfronteiriços ou como parte de uma "narrativa ambientalista". Intensifica-se então o apelo à criação de novas instituições no plano internacional global para lidar com a problemática relacionada com o impacto da questão hídrica e com a partilha de recursos hídricos entre Estados. Era chegado o momento para a realização da Primeira Conferência da Organização das Nações Unidas sobre Água e Ambiente, que teve lugar em Dublin, em 1992.

Dessa conferência resultaram os famosos Princípios de Dublin, que destacam a importância da participação pública e da adoção de mecanismos econômicos na gestão de recursos hídricos:

Watercourses for Purposes other than Navigation (conhecida como Declaração de Madrid de 191 I), a qual, apesar de não ser um instrumento convencional, é precursora no tratamento jurídico dos recursos hídricos no âmbito internacional. 
( I ) A água é um recurso finito e vulnerável, essencial para a manutenção da vida, do desenvolvimento e do ambiente;

(2) A gestão e o desenvolvimento dos recursos hídricos devem ser baseados no enfoque participativo, envolvendo usuários, projetistas e governos de todos os níveis;

(3) As mulheres têm um papel fundamental na administração, gestão e proteção dos recursos hídricos; e

(4) A água tem valor económico em todos os seus usos e deve ser reconhecida como um bem econômico.

A conferência de Dublin foi preparatória da Cimeira da Terra (Earth Summit), ou conferência do Rio de Janeiro, de 1992, no âmbito da qual se adoptou a conhecida Agenda 2 I . A Agenda 2 I contempla um capítulo sobre recursos hídricos (Capítulo I 8), que revela intensa influência do Plano de Ação de Mar del Plata, supramencionado.

Em 1997, a Assembleia Geral da Organização das Nações Unidas aprovou a Convenção da Organização das Nações Unidas sobre o Direito Relativo à Utilização dos Cursos de Água Internacionais para fins Diversos dos de Navegação ( 1997 UN International Watercourses Convention), que entrou em vigor em 2014 . Essa convenção constitui um marco no Direito Internacional dos recursos hídricos, não somente em virtude de princípios geralmente aceites que nela se encontram contemplados, mas também porque reflecte princípios de direito consuetudinário internacional quanto ao tema. Observemo-la mais de perto.

\subsection{O uso "razoável e equitativo" dos recursos hídricos partilhados e a Convenção da Organização das Nações Unidas, de 1997, relativa à utilização dos cursos de águas internacionais para fins diversos dos da navegação}

A utilização de cursos de águas internacionais para fins diversos da navegação é matéria sujeita ao Direito Internacional, e a necessidade de harmonização de usos entre Estados com direitos de soberania sobre rios partilhados fez com que se fossem formando normas consuetudinárias, que foram amplificando a sua força por meio da aplicação por jurisdições internacionais.

Com efeito, logo após a assinatura da Convenção da Organização das Nações Unidas, de 1997, mas bem antes da sua entrada em vigor na ordem internacional, a Corte Internacional de Justiça começou a aplicá-la. No caso Gabčíkovo-Nagymaros Project (1997), que opôs Hungria e Eslováquia, a Corte decidiu que o princípio da utilização razoável e equitativa (fair and equitable use), um dos pilares da Convenção, constitui um princípio básico de Direito Internacional, que se impõe, independentemente de consagração convencional, a todos os Estados que partilhem recursos hídricos. $\bigcirc$ mesmo princípio foi reiterado no caso Pulp Mills on river Uruguay (20।0), onde se enfrentaram Argentina e Uruguay. 
A Convenção contém um total de trinta e sete artigos - além de um anexo com catorze artigos sobre arbitragem -, incluindo princípios e regras substantivas e procedimentais, os quais dão corpo ao principal quadro normativo sobre o tema do aproveitamento de recursos hídricos compartilhados. Detenhamo-nos um pouco no seu elenco.

Do ponto de vista substantivo, o quadro normativo contém três princípios estruturantes: a utilização equitativa e razoável dos recursos naturais (artigo 5), a obrigação de não causar dano significativo ao ambiente (artigo 7) e a obrigação de proteção e preservação do ecossistema (artigo 20). Em primeiro lugar, os Estados que partilhem recursos hídricos têm direito de aproveitamento equitativo e razoável dos usos e benefícios das águas internacionais compartilhadas (com base numa lógica de igualdade de direitos). Trata-se de um contraponto ao princípio da soberania permanente e é considerado um princípio básico em sede de uso de recursos compartilhados.

Este princípio conheceu um primeiro afloramento na dimensão da igualdade dos Estados ribeirinhos. Com efeito, o Tribunal Permanente de Justiça Internacional, no caso Territorial Jurisdiction of the International Commission of the River Oder, em 1929, afirmou o seguinte:

[the] community of interest in a navigable river becomes the basis of a common legal right, the essential features of which are the perfect equality of all riparian States in the user of the whole course of the river and the exclusion of any preferential privilege of any one riparian State in relation to the others.

Mais tarde, permanecendo na abordagem ligada à igualdade dos Estados, registra-se nova pronúncia no caso Lac Lanoux, uma arbitragem que opôs a França à Espanha, num litígio que envolvia um lago situado em terras gaulesas alimentado por um rio proveniente de Espanha. Nessa decisão, sublinhou-se a importância de consultas mútuas sempre que esteja em causa a afectação significativa do caudal de um rio internacional, além de se reafirmar o princípio de que os Estados têm um direito de aproveitamento que é simultaneamente um dever de gestão equitativa:

More than thirty publicists are listed in the Memorial as supporting the view that a prior agreement is mandatory before a riparian may effect a substantial change in the régime of the Maters of international rivers and lakes. It is recognized by the Spanish Government that different authors justify their views on the basis of different theories, but the conclusion is reached that they all agree on the basic proposition that international law, apart from treaty, sanctions not only the equality of rights of coriparians, but also the necessity of prior agreement among coriparians, whenever a substantial alteration of the system of the waters is contemplated. 
Mais recentemente, e como se começou por observar, o Tribunal Internacional de Justiça voltou a fazer uso do princípio, no caso Gabcikovo-Nagymaros Project ( 1997 ), crismando-o com a designação que actualmente ostenta em vários documentos internacionais ("equitable and reasonable share"):

85. In the view of the Court, an important consideration is that the effects of a countermeasure must be commensurate with the injury suffered, taking account of the rights in question.

(...) Modern development of international law has strengthened this principle for non-navigational uses of international watercourses as well, as evidenced by the adoption of the Convention of 21 May 1997 on the Law of the NonNavigational Uses of International Watercourses by the United Nations General Assembly.

The Court considers that Czechoslovakia, by unilaterally assuming control of a shared resource, and thereby depriving Hungary of its right to an equitable and reasonable share of the natural resources of the Danube - with the continuing effects of the diversion of these waters on the ecology of the riparian area of the Szigetkoz - failed to respect the proportionality which is required by international law.

Deve-se realçar que a evolução mais recente — ver infra — denota uma espécie de transmutação do princípio do uso razoável e equitativo de recursos hídricos entre Estados com cursos ou massas de água partilhados num princípio de gestão racional dos recursos hídricos a todos os recursos, e não somente aos partilhados (cfr., maxime, nas Berlin Rules, de 2004). As preocupações ambientais têm estado na base dessa nova compreensão do princípio, desligada dos aspectos típicos da soberania recentrados na importância da água como recurso vital à sobrevivência de pessoas e ecossistemas.

Quanto ao princípio da proibição de causar dano (aos recursos hídricos), em segundo lugar, este se traduz em que os Estados devem adoptar todas as medidas apropriadas para prevenir e evitar qualquer dano ambiental significativo a outro Estado. Essa norma encontra a sua raiz no famoso caso Trail Smelter ( $1938 / 4$ I), do qual se extrai o princípio de que se uma actividade sediada num Estado provocar comprovadamente um dano sério em pessoas ou património de outro Estado, o primeiro incorre em responsabilidade internacional para com o segundo.

Esse princípio acarreta uma obrigação de "devida diligência" ("due diligence") por parte dos Estados no que concerne à utilização de sua porção equitativa e razoável dos recursos, que é tanto um dever substantivo imediato (v.g., não represamento das águas ou desvio dos cursos dos rios partilhados) como um dever de vigilância de actividades de terceiros (v.g., fiscalização de actividades industriais potencialmente poluentes). Acresce a obrigação de prevenir, reduzir e controlar a poluição das águas internacionais que podem causar prejuízo significativo ("significant harm") a outro Estado, por força do 
artigo 2 I da Convenção.

Em terceiro lugar e por fim, de acordo com o princípio da proteção do ecossistema, os Estados têm a obrigação de proteger os ecossistemas relacionados com águas internacionais, por força do artigo 20. Essa obrigação é uma aplicação do princípio da prevenção, o qual determina que os Estados adotem medidas antecipativas contra ameaças sérias de danos irreversíveis aos ecossistemas de águas internacionais.

Do ponto de vista procedimental, a Convenção estabelece normas relacionadas com a utilização de águas internacionais. Essas normas constituem parte essencial do aparato institucional para a alocação equitativa de recursos hídricos e têm natureza flexível. As obrigações decorrentes dessas normas incluem: obrigações de cooperar (artigo $8^{\circ}$ ), de notificação prévia (artigo 12), de consultar (artigo 17) e de trocar informações sobre o conteúdo de projetos hidráulicos (artigos $9^{\circ}$ e II). Ao cabo e ao resto, trata-se do modus operandi descrito no Draft articles on prevention of transboundary harm from hazardous activities, submetido pela Comissão de Direito Internacional à Assembleia Geral da Organização das Nações Unidas, em 200 I, uma verdadeira pauta de due diligence internacional no tocante aos deveres de prevenção de danos decorrentes de actividades perigosas para o ambiente.

Outro aspecto importante da Convenção é que esta se aplica tanto às águas superficiais como às águas subterrâneas. De acordo com a Convenção, o termo "watercourse" (curso de água) corresponde a um "sistema de superfície e águas subterrâneas que constituem, em razão da sua relação física, um todo unitário" (cfr. o artigo $2^{\circ}$ ).

Existem outros tratados internacionais com normas sobre recursos hídricos internacionais. Pode referir-se, a título de exemplo, a Convenção para proteção e uso de cursos de água transfronteiriços e rios internacionais, celebrada em Helsínquia, em 1992 (I 992 UN ECE Helsinki Convention), que constitui um caso particular, pois foi aberta à adesão de Estados não Europeus por um aditamento em vigor a partir de 2013. Esse Tratado e a Convenção, de 1997, têm basicamente o mesmo objeto e propósito: uso compartilhado e proteção dos recursos hídricos compartilhados. Adoptam, todavia, estratégias um pouco diferentes. A Convenção, de 1992, é direcionada para evitar impacto transfronteiriço e garantir a proteção do ambiente contra efeitos adversos significativos (cfr. o artigo I \%/2), e é bem mais detalhada quanto à proteção dos cursos de água internacionais em face de fenómenos de poluição. Em contrapartida, é mais concisa quanto à questão da utilização equitativa e razoável dos cursos de água abrangidos pela sua regulação. Assim se compreende a afirmação do relator da Convenção, de 1997, no sentido de que os dois tratados são complementares.

\subsection{Outras normas jurídicas "emergentes" de Direito Internacional aplicáveis a todos os recursos hídricos}

progressivo desenvolvimento do Direito Internacional Ambiental e do Direito Internacional dos Direitos Humanos reflecte um aprofundamento do papel do direito 
internacional consuetudinário aplicável em sede de recursos hídricos. Nesse sentido, é de ressaltar a revisão das Helsinki Rules (datadas de 1966) pela International Law Association, que empreendeu uma análise das normas costumeiras de direito internacional aplicáveis aos recursos hídricos em geral, num contexto de salvaguarda crescente de grupos vulneráveis e de preservação dos recursos hídricos enquanto recursos escassos e essenciais à sobrevivência dos ecossistemas - e não apenas enquanto bens de utilidades partilhadas por diversos Estados.

Vejamos quais os pontos em destaque nesse esforço de actualização dos princípios a utilizar em sede de Direito dos recursos hídricos, plasmados nas mais recentes Berlin Rules on Water Resources Law (2004):

i) Gestão Integrada e Conjuntiva dos Recursos Hídricos (GICRH)

De acordo com este princípio, plasmado no artigo $5^{\circ}$ das Berlin Rules, os Estados estão vinculados a efetuar os "melhores esforços" ("best efforts") para gerenciar os águas superficiais subterrâneas, e outras águas, de forma unificada e abrangente, bem como a integrar informações, dados e políticas públicas relacionadas com outros recursos na gestão de recursos hídricos das bacias internacionais. Por vezes referida como "abordagem holística", a Gestão Integrada e Conjuntiva dos Recursos Hídricos aproxima-se do Direito (Internacional) do Ambiente uma vez que apela à integração das políticas de gestão de recursos hídricos entre si e em conjugação com o aproveitamento de outros recursos, em atenção à minimização de impactos ambientais.

É discutível, sublinhe-se, a existência de uma obrigação de os Estados seguirem o princípio da Gestão Integrada e Conjuntiva dos Recursos Hídricos relativamente a recursos hídricos puramente internos, ou seja, não compartilhados. Certo é que se registram cada vez mais experiências com a implantação do IWRM em legislações domésticas, e esta fórmula mantém-se como um paradigma na gestão de recursos hídricos nos âmbitos local, nacional e internacional;

ii) Participação pública

Trata-se de um princípio geral de Direito Internacional do Ambiente, acolhido nas Berlin Rules nos artigos $4^{\circ}$ e 18, ao qual a Declaração do Rio 92 deu particular ênfase no artigo 10. No domínio da água, recurso vital à vida humana e à subsistência dos ecossistemas, a participação releva enquanto momento de dinamização da cidadania ambiental com vista a uma melhor tomada de decisões no tocante ao acesso à água e à racional repartição de usos do recurso. $\bigcirc$ artigo 18 incorpora a vertente do acesso à informação, direito procedimental imprescindível a uma participação plena, fazendo eco do disposto na Convenção da Aarhus, de 1998;

iii) Uso racional

Uso racional corresponde a uso duradouro e equilibrado. Essa noção de "reasonable use", abraçada pelos artigos 12 e 13 das Berlin Rules, destaca-se do gasto chavão do "desenvolvimento sustentável" porque é uma fórmula ecologicamente mais comprometida, uma vez que menos humanamente referenciada, e com um lastro histórico já significativo, pois está presente, desde a primeira hora, na Declaração de 
Estocolmo (vide os princípios 2, 3 e 5); consta da Convenção das Nações Unidas para o Direito do Mar, de 1982, no plano da gestão dos recursos piscícolas [cfr. os artigos 6 I/3 e I 19/1/a) ]; ; está inscrita no artigo 191/2 do Tratado sobre o Funcionamento da União Europeia, em sede de política de ambiente; e tem sede no artigo 10 da Convenção da Diversidade Biológica.

Não existindo fórmulas universais sobre a melhor forma de balanceamento de interesses ambientais com outros interesses (sociais e económicos, em especial), o artigo I 3 das Berlin Rules apresenta uma série de critérios que visam tornar operacional essa equação, desde critérios geográficos, climáticos, ecológicos, de aproveitamento humano directo e indirecto, sujeitos a uma ponderação de consequências e avaliação de alternativas;

iv) Proteção de grupos vulneráveis

Nos termos do artigo 20 das Berlin, os Estados devem adotar todas as medidas apropriadas para proteger os direitos, interesses e necessidades especiais de comunidades indígenas e outros grupos vulneráveis que podem ser afetados por projetos hídricos, tanto durante os trabalhos de implementação como após a sua conclusão. Não se pode esquecer de que as comunidades indígenas têm uma relação de especial proximidade com os recursos hídricos, sustento de vida, e por isso são especialmente afectados por quaisquer movimentações que lhes alterem a acessibilidade a tais recursos.

v) Dever de compensar comunidades realocadas

Corolário da dimensão social da água, este princípio, a que alude o artigo 21 das Berlin Rules, dita que os Estados têm o dever de compensar as pessoas e as comunidades realocadas na sequência da implantação de projetos hídricos, com vista a garantir adequada provisão para a preservação das condições básicas de vida dessas comunidades. As Berlin Rules manifestam especial preocupação com uma dimensão material dessa compensação, ou seja, não apenas a atribuição de quantias que compensem os bens perdidos, mas e sobretudo a compensação na medida da preservação das condições de vida que mantinham no local de onde foram desalojadas e da salvaguarda dos seus valores culturais;

vi) Obrigação de avaliar o impacto ambiental

Este princípio, inscrito no artigo 29 das Berlin Rules, assume hoje particular relevância. Com efeito, após a sua inclusão no elenco de princípios gerais de Direito do

\footnotetext{
${ }^{5}$ Disposições desenvolvidas no Agreement for the implementation of the provisions of the United Nations Convention on the Law of the Sea, of 10 december 1982, relating to the conservation and management of straddling fish stocks and highly migratory fish stocks, mais conhecido por Acordo de Nova lorque, de 1995 — vejam-se os considerados $2^{\circ}$ e $8^{\circ}$ do Preâmbulo, e os artigos $2^{\circ}$ e $5^{\circ}$, alíneas b) e h), referindo-se a "long-term conservation" ea "sustainable use".
} 
Ambiente no princípio 17 da Declaração do Rio 92, o princípio foi ganhando vulto e é hoje considerado princípio geral de origem consuetudinária pela Corte Internacional de Justiça - que assim o reconheceu nos casos Pulp mills on river Uruguay (20 I0) e Costa Rica vs Nicarágua e Nicarágua vs Costa Rica (20 I 5) - e pela Corte Internacional para o Direito do Mar (no Parecer n 17, de 20 I0, lavrado em sede de actividades dos Estados na Área: Responsibilities and obligations of States sponsoring persons and entities with respect to activities in the Area).

No tocante a recursos hídricos, o $n^{\circ} 2$ do artigo 29 indica os principais impactos que devem ser tidos em conta nos procedimentos de avaliação: I. Na saúde humana e na segurança; 2. No ambiente; 3. Nas actividades económicas, existentes e prováveis; 4. Nas condições socioculturais e socioeconómicas; 5. No uso racional das águas.

Deve-se sublinhar, malgrado a importância, tanto numa perspectiva social como ambiental, das directrizes estabelecidas nas Berlin Rules, que estamos em presença de um documento de soft law, que pretende influenciar as boas práticas dos Estados mas não constitui direito estrito. Tal como de "direito suave", estamos a falar quando transitamos para uma dimensão menos macro e mais micro da gestão racional da água: o abastecimento humano e o direito de acesso à água.

\section{AS INCERTEZAS SOBRE O DIREITO (DE ACESSO) ÀÁGUA:}

\section{I Direito à água ou direito de acesso à água?}

No âmbito internacional, é relativamente recente o enquadramento jurídico do direito à água, como direito humano ("the human right to water"). É bem verdade que o artigo 25 da Declaração Universal dos Direitos do Homem, de 1948, consagra a existência de um direito da pessoa a "um nível de vida suficiente para lhe assegurar e à sua família a saúde e o bem-estar, principalmente quanto à alimentação..." e que, por inferência, poder-se-ia argumentar que o direito à água estaria contido (ou faria parte) no direito à subsistência (ou à alimentação), no direito à saúde, ou mesmo no direito à vida. No entanto, somente a partir do final do século $X X$ o direito à água (no sentido do seu fundamento e do seu conteúdo normativo) vai ser objeto de uma tentativa de enquadramento jurídico específico que permita, apesar da complexidade que o envolve, determinar quais são as obrigações dos Estados quanto à sua realização e quais as consequentes implicações dessa consagração no plano das decisões sobre a utilização dos recursos hídricos.

O debate sobre o direito à água emerge de forma relevante no cenário internacional na Conferência das Nações Unidas de Mar del Plata, de 1977. A Resolução II da Conferência declara expressamente que "todas as pessoas, independentemente do seu estágio de desenvolvimento e da sua condição social e econômica, têm direito ao acesso à água potável em quantidade e qualidade correspondentes às suas necessidades básicas". Desde então, os debates na comunidade internacional sobre a existência e o 
conteúdo desse direito avançaram nas diversas conferências internacionais.

Dessas conferências, resultaram, na esmagadora maioria dos casos, documentos com a natureza de soft law. Quer isso dizer que as resoluções, declarações, planos de ação, decisões e recomendações adoptadas nesse âmbito carecem "per se" de vinculatividade ("enforceability") e não provocam, portanto, responsabilização internacional dos Estados em caso de incumprimento. Tal constatação não reduz a importância dessas declarações e afins; pelo contrário, elas constituem importante mecanismo de governança global e podem, eventualmente, constituir parte de um processo de produção normativa, a evidenciar a emergência de um "costume internacional”, ou mesmo amparar negociações e discussões prévias à celebração de acordos e convenções.

Facto é que subsiste incerteza sobre o reconhecimento de um direito à água - sobre os seus fundamentos, conteúdo normativo, forma de realização e alcance -, bem como sobre as implicações daí decorrentes acerca da alocação de recursos hídricos. A análise dessas questões passa necessariamente pelo enquadramento legal do direito à água, à luz do regime jurídico de proteção dos direitos humanos, seja pelo sistema da Organização das Nações Unidas, seja no contexto dos sistemas regionais ou de tratados específicos.

$\bigcirc$ regime jurídico geral de proteção internacional dos direitos humanos tem alicerces na Carta da Organização das Nações Unidas, que estabelece, no seu artigo I/3, o princípio do respeito pelos direitos humanos como princípio de direito internacional e, por conseguinte, incentiva a criação de órgãos para a sua efetivação. Como a Carta não definiu ou listou quais seriam esses direitos (apesar de se referir a eles nos artigos I/3, 55 e 56), foi posteriormente adotada, por Resolução da Assembleia Geral da Organização das Nações Unidas, a Declaração Universal dos Direitos do Homem, em 1948. Os direitos estabelecidos na DUDH foram posteriormente desenvolvidos num duplo plano, no Pacto Internacional sobre os Direitos Civis e Políticos (PIDCP) e no Pacto Internacional sobre os Direitos Econômicos, Sociais e Culturais (PIDES), ambos de 1966. Ora, em nenhum desses Pactos - sobretudo no primeiro - consta a referência a um "direito à água".

Somente em 2002 o Comitê sobre Direitos Econômicos, Sociais e Culturais da Organização das Nações Unidas (CDESC) adotou o Comentário Geral n 15 sobre o Direito à Água (artigos I I e 12 do PIDES). Deve-se mencionar que o Comentário I 5 afirma que

o direito humano à água traduz-se em que todas as pessoas devem usufruir de uma quantidade de água suficiente, segura, aceitável, a preços razoáveis e fisicamente acessível para usos pessoais e domésticos.

Comentário explicita ainda que a consagração desse direito gera obrigações para o Estado, nomeadamente de: 
- Respeitar o direito, abstendo-se de interferir directa ou indirectamente no seu gozo;

- Proteger o direito da interferência de terceiros;

- Promover o direito por meio de acções dirigidas directamente à plena realização deste, sem discriminações e com respeito pela igualdade entre os sexos.

Por outras palavras, e ressalvada a importância simbólica e pedagógica do Comentário Geral $n^{\circ}$ | 5, não é ainda claro se o direito à água e ao saneamento básico em bases aceitáveis, acessíveis e módicas, constitui um direito imediatamente exigível ou se traduz apenas um apelo aos Estados a que, progressivamente e sob reserva de condições financeiras, adoptem medidas para a implementação dessa tarefa. No que concerne às vinculações decorrentes do PIDES, os Estados têm obrigação de implementá-lo progressivamente, considerando os recursos disponíveis. Em contrapartida, caso a obrigação decorra diretamente do PIDCP, os Estados estão imediatamente constrangidos ao seu cumprimento, sendo certo que provisão protege indivíduos apenas em caso de ações arbitrárias dos Estados que possam colocar em risco a vida humana. Em muitos casos, a implementação dos direitos envolve o desenvolvimento de projetos de larga escala para atender às necessidades de populações carentes, o que torna complexa a afirmação da sua exigibilidade imediata e incondicional.

Porque o direito à água pressupõe desde logo a presença do elemento água no âmbito residencial do sujeito, e para torná-lo mais credível tem-se vindo a falar progressivamente de um direito de acesso à água. A efectivação desse direito envolve, num primeiro momento, a promoção da acessibilidade a um serviço, tendencialmente público ou privado, mas com preços regulados por uma entidade independente, de distribuição e fornecimento de água potável, ou seja, implica a existência de infraestruturas que possam levar a água de onde ela se encontre no território nacional aos locais de residência das populações. E essa operação pode estar não apenas técnica como financeiramente condicionada - o que perturba a afirmaçãa da exigibilidade do direito de acesso em determinados contextos de escassez de meios financeiros e/ou complexidade de adopção de soluções técnicas.

Num segundo momento, estando reunidas as condições técnicas e financeiras, cumpre observar alguns princípios para que esse direito de acesso à água possa significar o acesso à água de forma suficiente, segura e aceitável:

- A suficiência prende-se com a priorização de usos e o licenciamento prévio de títulos de utilização, por exemplo, dando-se preferência ao uso humano sobre usos industriais; preferindo-se apoiar a agricultura de produção biológica à agricultura extensiva; preterindo-se certas espécies de árvores, como o eucalipto, a outras, permitindo uma melhor distribuição de água pelos lençóis freáticos;

- A segurança está relacionada com a gestão das bacias hidrográficas e com os caudais de águas subterrâneas, os quais devem ser monitorizados conforme as 
condições climáticas, prevenindo situações de seca ou minimizando os seus efeitos;

- A aceitabilidade liga-se à qualidade de água, promovendo avaliação de impacto ambiental dos sistemas de captação e controlo de qualidade do abastecimento.

A questão dos preços razoáveis, por último, visa promover o equilíbrio entre as dimensões social e económica. $\bigcirc$ facto de a água ser um bem escasso não pode significar fazer repercutir o valor real de escassez no custo do bem, uma vez que ele é vital. Em contrapartida, a indispensabilidade da água à satisfação de necessidades básicas não pode implicar o seu fornecimento gratuito, pois a gratuitidade volver-se-ia rapidamente em desperdício. Cumpre, portanto, chegar a um valor que incuta no consumidor a consciência da necessidade de gestão racional, o que justifica a natureza pública do serviço de abastecimento ou, pelo menos, a regulação do preço por uma entidade pública.

Os preços podem, no entanto, variar, quer em razão dos custos de extracção, distribuição e tratamento, como em função das especiais carências de certos sectores da população. Em Portugal, uma das novidades do Orçamento de Estado para 2017, em discussão, é a introdução da "tarifa social da água", à semelhança do que sucede há alguns anos já com a "tarifa social da electricidade". Trata-se de garantir a cobrança de preços menos elevados a famílias e pessoas com rendimentos baixos, de forma a que a fraca capacidade económica não constitua obstáculo no acesso a um bem vital.

\section{2 dever de gestão racional do acesso à água}

Naturalmente que, existindo sistemas públicos de distribuição e abastecimento e em face da progressiva escassez do recurso em virtude do aquecimento global, são fundamentais políticas públicas, sistemáticas e estruturais, de promoção da gestão racional. Como se observou, o objectivo da suficiência de abastecimento assenta num pressuposto de racionalidade de escolhas que priorizem o acesso humano e garantam a afectação de recursos hídricos a actividades agrícolas e industriais adaptadas às características geográficas e climáticas da zona em questão (cfr. os critérios estabelecidos no artigo 13 das Berlin Rules, supramencionado, bem assim como o critério de preferência inerente do uso humano afirmado no artigo 14 destas).

Em Portugal, o artigo 8I/n da CRP incumbe o Governo de prosseguir uma política nacional da água, por meio de planeamento que assegure a gestão racional dos recursos hídricos. Estudos preliminares sobre o uso eficiente da água começaram a se desenvolver desde 2000-200 I e culminaram com a aprovação, pela Resolução do Conselho de Ministros I I3/2005, de 30 de junho, do Plano Nacional da Água, em cujos considerandos iniciais por várias vezes se sublinha o carácter escasso e simultaneamente estratégico do recurso, apelando-se ao seu uso "eficiente e parcimonioso". Esse Plano serviu de base à aprovação do Programa para o uso eficiente da água: bases e linhas orientadoras (PNUEA), aprovado pela mesma Resolução, que tem por objectivo promover um conjunto de medidas de aproveitamento racional do recurso. 


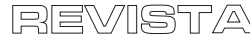

As quatro áreas de intervenção designadas foram: Medição e reconversão de equipamentos de utilização da água; Sensibilização, informação e educação; Regulamentação e normalização; e Formação e apoio técnico. Em cada uma destas áreas, deverão ser implementadas medidas que atenderão a prioridades de nível elevado, médio e baixo, tendo em consideração, sobretudo, a poupança de água que seja susceptível de promover. As metas estabelecidas pelo PNUE apontam para um acréscimo de eficiência na utilização da água em três planos: no consumo humano, de 60\% para 80\%; no consumo agrícola, de 60\% para 65\%; no consumo industrial, de $70 \%$ para $85 \%$, todos a verificar num prazo de 10 anos (20 I 5), com eventuais variações locais em razão da variabilidade geográfica do país.

A promoção do acesso à água é tarefa pública; a sua utilização racional é dever de todos. Medidas como a instalação de contadores inteligentes (que premiam ou agravam o custo do bem); a alteração de hábitos de consumo em actividades domésticas como banhos, lavagem de roupa e louça, lavagem de veículos e pavimentos; a introdução de práticas de reutilização de água na confecção de alimentos (água em que se cozem vegetais pode ser reutilizada, em novas cozeduras ou a fazer sopa); a adaptação dos sistemas de rega a mecanismos que evitem o desperdício - todas essas medidas contribuem para a efectivação do direito de acesso à água, por meio de uma utilização racional e equitativa do recurso por todos nós.

\section{REFERÊNCIAS}

BISWAS, Asit K.; TORTAJADA, Cecília. Water Security, climate change and sustainable development, 2016.

MCCAFFREY, Stephen. The Law of International Watercourses and Non Navigational Uses, 2001 .

SALETH, Maria e DINAR, Ariel. The Institutional Economics of Water, 2004.

VIVAS, Eduardo e MAIA, Rodrigo. A Gestão de Escassez e Secas Enquadrando as Alterações Climaticas/ The Water Scarcity and Droughts' Management Framing Climate Change Issues, 20 10. Disponível em: <http://www.aprh.pt/rh/pdf/rh3 I_nl2.pdf. >. Acesso em: I out. 2016.

Recebido em: 07/06/2017

Aprovado em: 30/06/2017 